\title{
Hydroxyapatite phagocytosis by human polymorphonuclear leucocytes
}

\author{
KENNETH H. MAURER, AND H. RALPH SCHUMACHER
}

From the Section of Rheumatology, Veteran's Administration Hospital, and the Department of Medicine $\vec{\odot}$ Hospital of the University of Pennsylvania, Philadelphia, Pennsylvania, USA

SUMMARY Hydroxyapatite crystals were incubated with human polymorphonuclear leucocytes an $\frac{0}{\Phi}$ samples examined by light and electron microscopy after 3, 8, 30, and 120 minutes' incubation $\omega_{\infty}^{\omega}$ Phagocytosis of crystals occurred at 3 minutes and increased with incubation. Degranulation of neutrophils, loss of cytoplasmic density, and cell necrosis were greatest in cells mixed with apatite and increased with time. Avid in vitro phagocytosis of hydroxyapatite crystals lends further suppori to the potential of these crystals as causes of human arthritis.

Apatite crystals have been implicated in periarthritis (McCarty and Gatter, 1966) and have recently been suggested as a cause of crystal induced arthropathy (Dieppe et al., 1976; Schumacher et al., 1977; Amor et al., 1977). Previous studies have shown that monosodium urate crystals and calcium pyrophosphate dihydrate crystals incubated with human white blood cells are phagocytosed and lead to different degrees of necrosis of the phagocytic cells (Schumacher and Phelps, 1971; Schumacher et al., 1975). In this report we describe our results from incubation of hydroxyapatite crystals with human white blood cells and the sequential changes observed after crystal phagocytosis.

\section{Materials and methods}

Hydroxyapatite crystals (type I) suspended in $0.001 \mathrm{M}$ phosphate buffer at $\mathrm{pH} 6.8$ were obtained from Sigma Chemical Co., St. Louis, Missouri, Crystals were present in $0.4-15 \mu \mathrm{m}$ clumps; the hydroxyapatite was heated for 3 hours at $180^{\circ} \mathrm{C}$ to eliminate any possible pyrogenic material.

Human polymorphonuclear leucocytes (PMNL) were separated from heparinised venous blood by dextran sedimentation (Klein, 1958) and suspended in the resulting plasma-heparin-dextran at a final concentration of 13400 cells per $\mathrm{mm}^{3}$. As in previous experiments with urates and calcium pyrophosphates the suspension in addition to PMNLs contained

Accepted for publication 17 March 1978.

Correspondence to Dr Kenneth $\mathbf{H}$. Maurer, Arthritis and Rheumatic Disease Associates, PA, 1860 Greentree Road, Cherry Hill, New Jersey 08003, USA. small numbers of monocytes, eosinophils, platelets and erythrocytes.

$1 \mathrm{mg}$ of hydroxyapatite crystals was added to 4 of eight $160 \times 13 \mathrm{~mm}$ tubes containing $1.0 \mathrm{ml}$ aliquots of the cell suspension. All tubes were centrifuged ao $350 \mathrm{~g}$ for 2.5 minutes and then incubated at $37^{\circ} \mathrm{Cs}$ Paired tubes with and without crystals were incuo bated for 3, 8, 30, and 120 minutes. After each time incubation aliquots were removed for light microo scopic examination. $8 \mathrm{ml}$ of $\frac{1}{2}$ strength Karnovsky' $\overrightarrow{\overrightarrow{\mathrm{E}}}$ fixative was then added to each tube for electro microscopy. After brief fixation specimens were diced into $1 \times 1 \mathrm{~mm}$ pieces, fixed in $\frac{1}{2}$ strengt fixative diluted $1: 1$ with $0 \cdot 1$ cacodylate buffer aఖ pH 7.4 for 4 hours, postfixed in cold Palade's osmium veronal for 2 hours, dehydrated with al 3 cohol, and embedded in Epon 812. Ultrathin sections were prepared on an LKB ultramicrotome. Grids were examined on a Zeiss EM 10 electron micro scope. The percentage of cells with phagocytosis of crystals and with cells necrosis was estimated bo counting 50-100 cells from each tube.

Four wet smears were made from each of the aliquots taken before fixation and examined byo phase and compensated polarised light microsn copy. The percentage of cells containing hydroxy $\bar{\sigma}$ apatite was calculated after examining 400 cells front each tube.

\section{Results}

Three minutes after the crystals were added to the्D cell syspension phagocytosis could be appreciate of by both light and electron microscopy (Table 1 ) 
Table 1 Hydroxyapatite incubation with human polymorphonuclear cells

\begin{tabular}{lcccc}
\hline \% cells with crystals & \multicolumn{5}{c}{ Time of incubation in minutes } \\
\cline { 2 - 5 } & 3 & 8 & 30 & 120 \\
\hline & $\%$ & $\%$ & $\%$ & $\%$ \\
Light microscopy & 3 & 6 & 8 & 10 \\
Electron microscopy & 10 & 12 & 49 & 51 \\
\% cell necrosis & 12 & 9 & 10 & 19 \\
Control & 12 & 10 & 38 & 36 \\
Cells mixed with crystals & & & & \\
\hline
\end{tabular}

As noted in the Table, estimated percentages of cells containing phagocytosed crystals tend to increase with time. By light microscopy apatite clumps, whether intra- or extracellular, appeared globular or rod like with irregular margins. Most crystal clumps were not birefringent, but occasional clumps did have weakly positive or negative birefringence.

By electron microscopy, after 3 minutes, polymorphonuclear leucocyte processes were seen enfolding extracellular apatite. Other PMNLs examined at 3 minutes already had some apatite entirely within cell vacuoles. Both rod-like clumps and small clusters of crystals continued to be seen in the process or being enfolded and phagocytosed at all time periods examined (Figs. 1-3).

There was some evidence of degranulation of

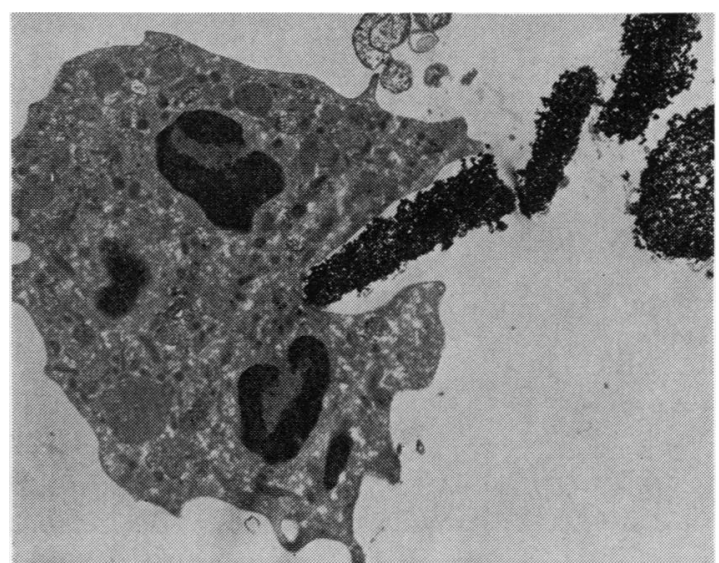

Fig. 1 Dark rod-like clump of hydroxyapatite crystals being enfolded by polymorphonuclear cell processes. Electron micrograph, $\times$ 7100, 30 minutes' incubation.

neutrophils and loss of cytoplasmic density in all tubes at 3 minutes and throughout the study: this was greatest in the cells mixed with apatite and appeared to increase with time. Cells mixed with apatite without identified phagocytosis of crystals

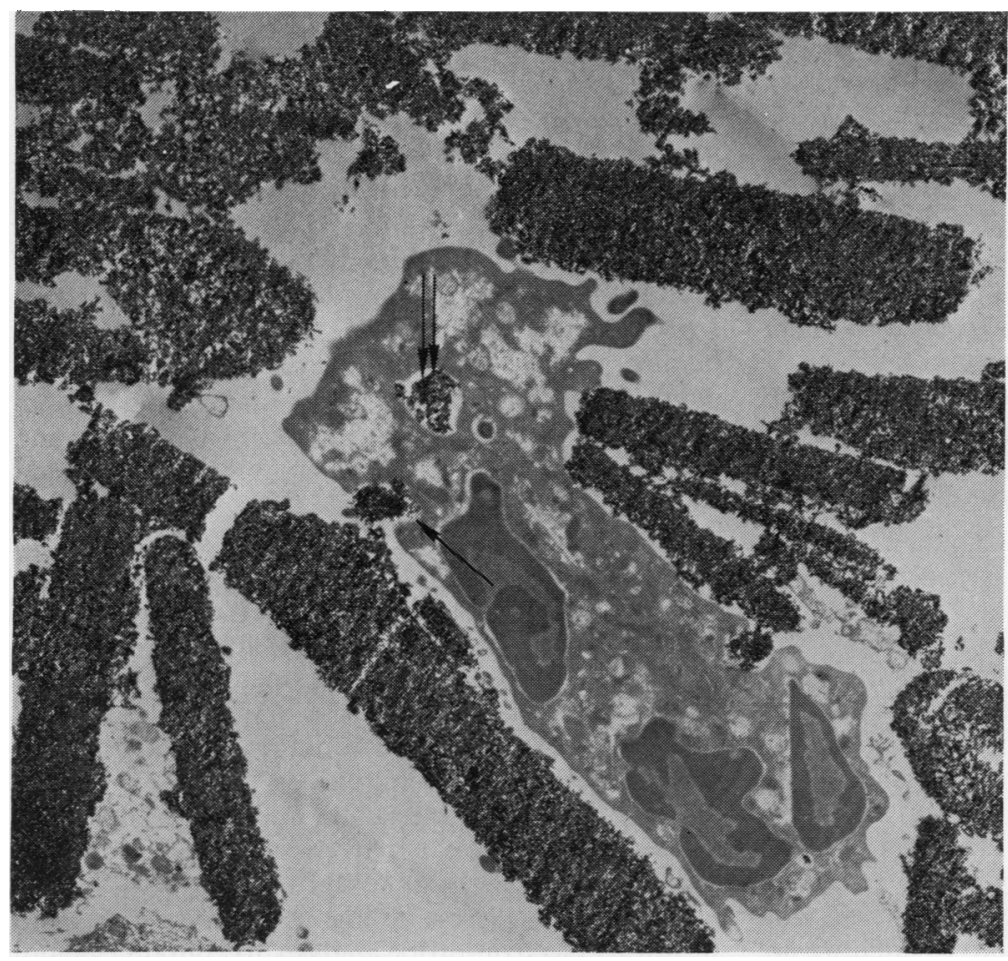

Fig. 2 Large rod shaped extracellular clumps of hydroxyapatite with smaller clumps in a well defined phagosome (double arrow) and in process or being enfolded by cell processes (single arrow). 


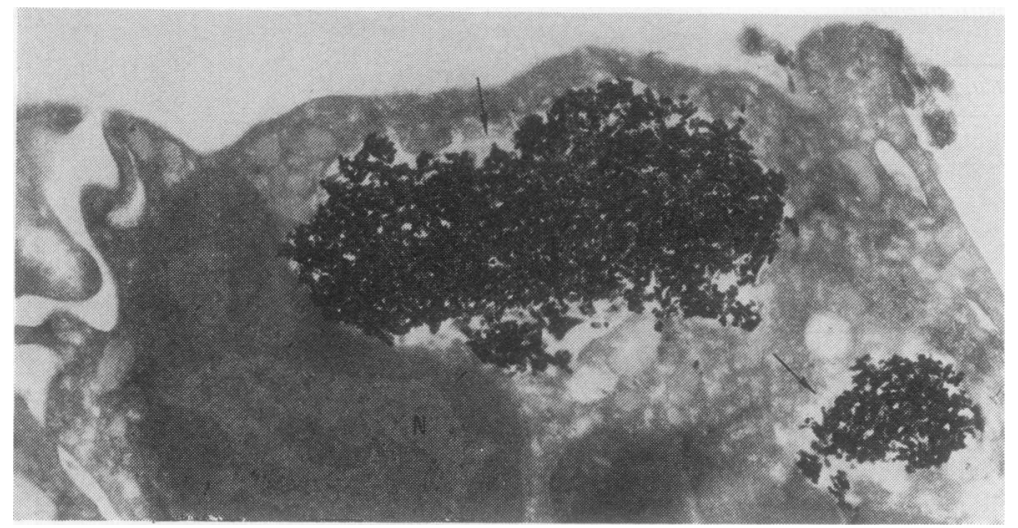

Fig. 3 Clump of apatite crystal in phagosome of polymorpho nuclear cell. Clear vacuoles adjacent to the phagosome probably are a result of degranie lation. Phagosomal membranes are indistinct at several areas (arrows) $N=$ nucleus. Electron micrograph $\times 20000,8$ minute incubation.

also had prominent degranulation but one could not be certain that an adjacent section of the cell would not be shown to contain crystals.

Dense bodies were only infrequently seen in phagosomes with crystal clumps. Phagosomal membranes were sometimes not well defined around apatite clumps, but similar indistinct phagosomal membranes were also occasionally seen in controls, presumably at least in part due to tangental cutting.

Only disruption of the cell with loss of external cell membranes was considered evidence of cell necrosis for this study. Some cell necrosis was identifiable by electron microscopy at 3 minutes, probably reflecting cell damage during separation. The percentage of necrotic cells estimated by electron microscopy increased with time, reaching $35 \%$ at 120 minutes in specimens mixed with crystals compared to only $19 \%$ in controls (Table 1). Where crystal clumps were seen within necrotic cells, they were generally large clumps (Fig. 4). No external lysis of cell membrane was seen related to direct contact from an extra cellular crystal clump.

Monocytes, eosinophils, and platelets were also present, and these also occasionally phagocytosed crystals. Monocytes and eosinophils containing crystals did not show necrosis or loss of cytoplamic density.

\section{Discussion}

These in vitro studies show that clumps of hydroxyapatite crystals are readily phagocytosed by human polymorphonuclear leucocytes and also by other cells. The smallest clumps of crystals would not be detected by light microscopy and probably account for the lower percentage of cells identified as containing crystals by light microscopy than by electron microscopy. Small clumps, especially when not birefringent, would also be difficult to identify in synovial or bursal fluids. Thus, the possible impor? tance of apatite crystals in joint diseases has only been widely recognised after electron microscopys studies. It should be noted that sodium urate (Schu macher et al., 1975b) and calcium pyrophosphate crystals (Honig et al., 1977) in human gout and pseu $\vec{c}$ dogout are occasionally so small that they also ares recognised only by electron microscopy.

Although cells mixed with hydroxyapatite did show greater necrosis than control cells, and necros sis did seem to be associated with crystal phago cytosis, we can not yet be certain about mechanisms involved. Urate crystals appear to lyse phagosoma membranes (Schumacher and Phelps, 1971; Walling $\overrightarrow{\overrightarrow{0}}$ ford and McCarty, 1971; Weissman, 1971; Schu 3 macher, 1977). Some loss of phagosomal membranes? was seen in these experiments with apatite, bu? further studies will be needed to establish the rolew of this type of cell injury with apatite. Clumps of crystals of several microns in length seemed to be associated with most necrotic cells, so that there mays be an optimal clump size for phagocytosis and celf damage. The possible role of crystal size on sodium urate and calcium pyrophosphate phagocytosis andP cell damage has been examined (Schumacher et al. $\frac{D}{0}$ 1975a).

Apatite crystals from human joint effusions have often been surrounded by electron dense materiah (Schumacher, 1977; Schumacher et al., 1977). That was not seen in this in vitro system even though ${ }^{\omega}$ there was some serum in the incubating medium. Dense material coating urate crystals from gout $y$ ? joints has been shown to contain immunoglobulinse (Hasselbacher and Schumacher, 1976). Immunoglobulin or other materials bound to the surface of urate crystals in vivo may increase the avidity of phagocytosis (Kozin and McCarty, 1976).

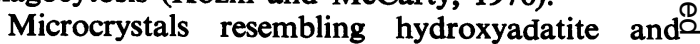
shown by electron-probe analysis to contain calcium? 


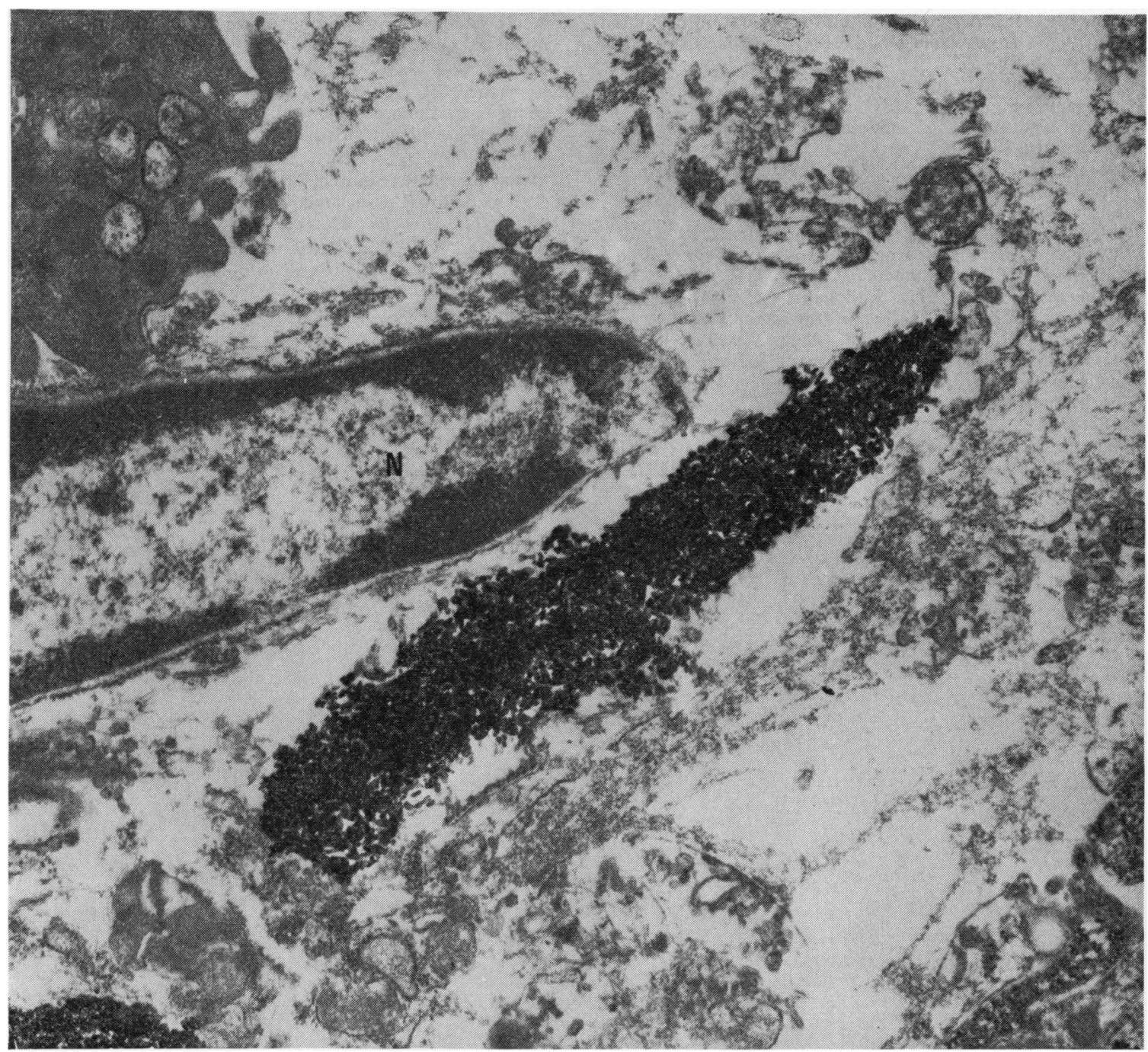

Fig. 4 Necrotic polymorphonuclear cell with large clump of apatite crystals. Most external cell membrane and phagosomal membrane is lysed. $N=$ nucleus. There is an intact cell in the upper left-hand corner.

and phosphorous in a ratio consistent with apatite have been demonstrated in synovial fluid leucocytes (Schumacher et al., 1977). Hydroxyapatite crystals are associated with an acute synovitis when injected into canine knee joints. (Schumacher et al., 1976) and cause acute inflammation when injected into human skin and rat pleura (Dieppe et al., 1976). Our study demonstrating ready in vitro phagocytosis of hydroxyapatite crystal clumps adds further support to the comparability of these clumps with urate and calcium pyrophosphate crystals as potential causes of human arthritis.

\section{References}

Amor, B., Cherot, A., and Del Barre, F. (1967). Le rhumatisme hydroxyapatite. Revue du Rhumatisme et des Maladies ostéo-articulaires, 44, 309-316.

Dieppe, P. A., Crocker, P., Huskisson, E. C., and Willoughby (1976). Apatite deposition disease. Lancet, 1, 266-269.

Hasselbacher, P., and Schumacher, H. R. (1976). Localization of immunoglobulin in gout tophi by immunohistology and on the surface of monosodium urate crystals by immune agglutination. Arthritis and Rheumatism, 19, 802 (Abst.).

Honig, S., Gorevic, P., Hoffsten, S., and Weissman, G. (1977). Crystal deposition disease. American Journal of Medicine, 63, 161-164, 


\section{Maurer, Schumacher}

Klein, E. (1958). A simple method for separation of human leukocytes from whole blood. American Journal of Pathology, 29, 550-552.

Kozin, F., and McCarthy, D. J. (1976). Protein absorption to monosodium urate (MSU) crystals: a possible mechanism of crystal induced inflammation. Arthritis and Rheumatism, 10, 805-806 (Abst.).

McCarty, D. J., and Gatter, R. A. (1966). Recurrent acute inflammation associated with focal apatite crystal deposition. Arthritis and Rheumatism, 9, 804-819.

Phelps, P., Steele, A. D., and McCarty, Jr., D. J. (1968). Compensated polarized light microscopy. Journal of the American Medical Association, 203, 166-170.

Schumacher, H. R. (1977). Pathogenesis of crystal-induced synovitis. Clinics in Rheumatic Diseases, 3, 105-131.

Schumacher, H. R., Fishbein, P., Phelps, P., Tse, R., and Krauser, R. (1975a). Comparison of sodium urate and calcium pyrophosphate crystal phagocytosis by polymorphonuclear leukocytes. Arthritis and Rheumatism, 18, 783-792.

Schumacher, H. R., Jimenez, S. A., Gibson, R., Pascual, E., Traycoff, R., Dorwart, B. B., and Reginato, A. (1975b).
Acute gouty arthritis without urate crystals identified on initial examination of synovial fluid. Arthritis and Rheumatism, 18, 603-612.

Schumacher, H. R., and Phelps, P. (1971). Sequential changes in human polymorphonuclear leukocytes after $\bar{\sigma}$ urate crystal phagocytosis. Arthritis and Rheumatism, 24, 513-526.

Schumacher, H. R., Somlyo, A. P., Tse, R., and Maurer, K (1977). Arthritis associated with apatite crystals. Annals ڤे of Internal Medicine, 87, 411-416.

Schumacher, H. R., Tse, R., Reginato, A. J., Miller, J., and Maurer, K. (1976). Hydroxyapatite-like crystals in synovial fluid cell vacuoles: a suspected new cause for crystal $\omega$ induced arthritis. Arthritis and Rheumatism, 19, 821 (Abst.).

Wallingford, W. R., and McCarty, D. J. (1971). Differential ç membranolytic effects of microcrystalline sodium urate and calcium pyrophosphate dihydrate. Journal of Experi- $\dot{\infty}$
mental Medicine, 133, 100-112.

Weissman, G. (1971). The molecular basis of gout. Hospital $\subseteq$ Practice, 6, 43-52. 